\title{
Problems of Electric Power System Management taking into account Sources Distributed Generation
}

\author{
Muhayo Toshkhodzhaeva ${ }^{1, *}$, Elena Gracheva ${ }^{2}$, Okhunbobo Rahimov $^{1}$, and Shakhboz Dadabaev ${ }^{1}$ \\ ${ }^{1}$ Department of Power Supply and Automation, Khujand Polytechnic Institute of the Tajik Technical University Named after Academician \\ M.S. Osimi, Khujand 735700, Tajikistan \\ ${ }^{2}$ Department Power supply of industrial enterprises Kazan State Energy University, Kazan 420066, Russian Federation
}

\begin{abstract}
This article provides a brief overview of the existing problems of managing the electric power system, taking into account the sources of distributed generation. The features of centralized and decentralized power supply systems are considered from the point of view of changing operating conditions, in particular, eliminating the consequences of technological violations. The main goals of the electric power system management have been determined, regardless of the number of sources and the category of consumers in terms of power supply reliability, as well as in emergency and post-emergency modes. The basic principles and sequence of power system management are presented. An algorithm for the efficiency of operation and dispatch control of the power system is considered, methods for ensuring the selective operation of relay protection and automation devices in the presence of several generating capacities are presented. A fragment of an electrical network with four energy sources is shown and the main measures to ensure its normal functioning are proposed.
\end{abstract}

\section{Introduction}

In the developed countries of the world (USA, Denmark, Norway, Germany, etc.), along with the development of centralized power supply, systems with local energy sources are intensively developing. The purpose of this article is to review and analyze the key problems of managing the electric power system when connecting several local energy sources to the electric network. In the process of reforming the electric power system, i.e. Under the conditions of the transition from a traditional system to a decentralized one, the management of the system becomes more complicated, because not only the distribution of the power flow changes, but also the problem of timely elimination of emergency modes arises due to completely different conditions [1].

Under normal operating conditions, the main task of controlling the electrical system is to provide all consumers with energy, regardless of the number of generating sources, while observing quality and reliability standards with maximum efficiency, which is carried out by operating personnel and various automatic devices for normal operation [2, 3 and 4]. In emergency mode, the goal of controlling the electrical system is to minimize losses from limiting power consumption and damage to electrical equipment due to the timely mobilization of the resource of impacts and their optimal use. For this, in an emergency mode requires quick elimination of the source of disturbance, as well as localization of the consequences of the accident. The control is carried out by devices of relay protection and emergency automation. In the post-accident mode, the task of managing the electrical system is to prevent the development of an accident with measures that meet the minimum damage to the electrical system and consumers. In the last recovery mode, control of the electrical system consists in returning the electrical power system to normal operation [5, 6 and 7].

\section{Modeling and simulation result}

In the case of several parallel operating sources functioning in the electric power system, the basic principles of its control should not be violated, namely $[8,9]$ :

- current of the required operating mode;

- production of switchings, starts and disconnections;

- localization of accidents and restoration of the operating mode;

- preparation for the production of emergency repair work.

The sequence of power system control is shown in Figure 1.

As can be seen from Figure 1, the main task of the operational dispatching personnel is to timely eliminate the consequences of accidents and restore the normal operation of the electric power system.

The operating and dispatching personnel of the power system is a key link in the process of timely elimination of technological violations, and the reduction of the severity of accidents, restoration of the system and the efficiency of operation depend on their professional

*Corresponding author: shukrona14 01 2011@ mail.ru 


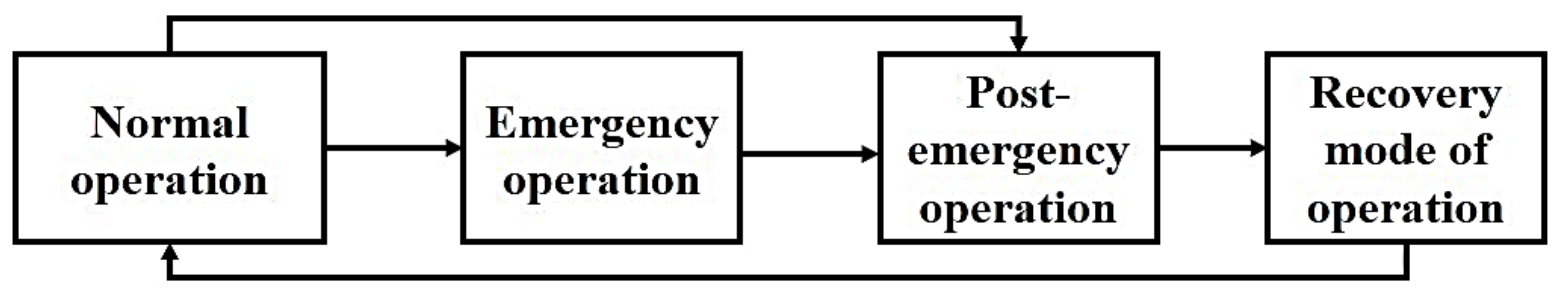

Fig. 1.Sequence of control of the electric power system

actions [8, 10 and 11]. The algorithm for the efficiency of operation and dispatch control of the power system is shown in Figure 2.

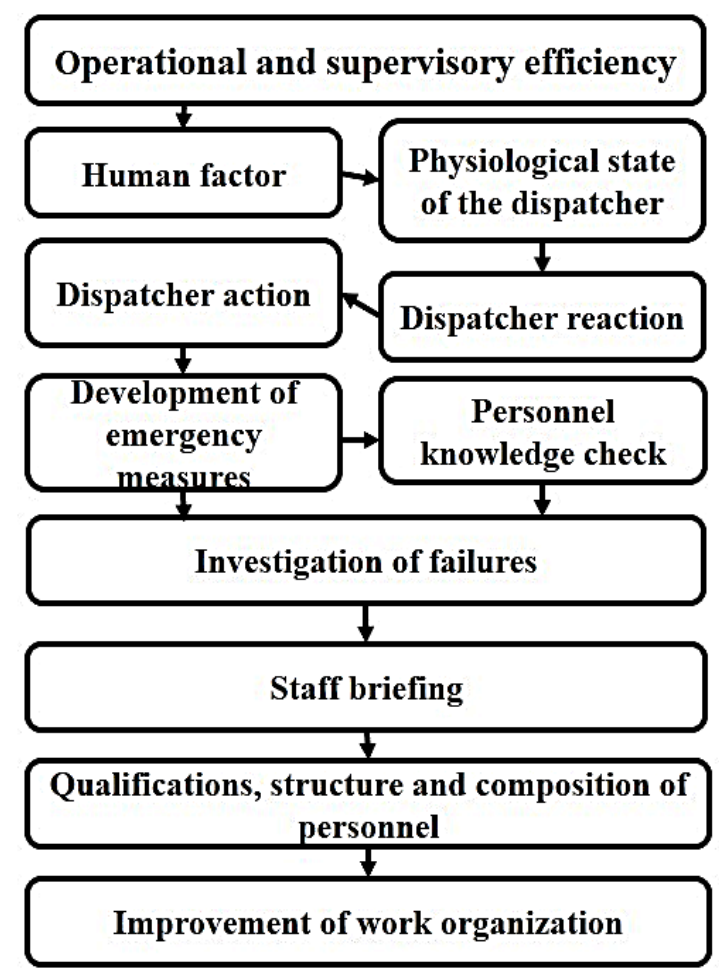

Fig. 2.Algorithm of the efficiency of operation and dispatch control of the power system.

As the presented diagram shows, the efficiency of the power system operation is influenced by a number of factors, including: the human factor, correct development of emergency measures, actions and reactions of the dispatcher, etc $[12,13]$.

With a centralized scheme of an electric power system, the distribution of the power flow is carried out from one conventional source to consumers and the selectivity of the relay protection settings is adjusted according to their response time. In the case of several sources in one system, ensuring the selectivity of relay protection and automation devices is a complex mechanism for a number of reasons:

1. The consumer of electricity can simultaneously serve as a source of electricity, therefore, a strict adjustment of the relay protection and control devices is required, which is consistent with the setting maps of the operational dispatch service;
2. In case of violation of synchronization in one of the sources, there is a probability of strong disturbances in the power system, i.e. there is a cascade development of the accident;

3. In case of failure of the local energy source, the power system must provide the required power for this consumer;

4. The need to maintain permissible network frequency parameters during emergency and postemergency power system modes.

As an example, consider a fragment of an electrical network with four sources of electricity, which is shown in Figure 3.

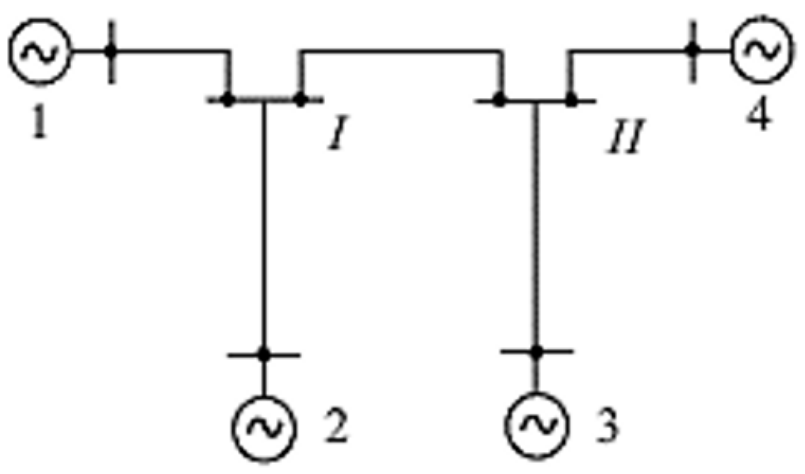

Fig. 3.Fragment of an electrical network with four sources of electricity.

When the stability of the electric power system 1 is disturbed, the electrical center is located near the buses I and the stability of the system 2 is disturbed. There are three electrical centers caused by the asynchronous regime between the generators $1-2 ; 1-3.4$ and 2-3.4. The last electrical center may be close to buses II, which violates the stability between systems 3 and 4 . Therefore, the violation of stability on one connection can cause an avalanche secondary asynchronous mode in a number of sections of the power system network. When there is a possibility of the occurrence of secondary asynchronous modes, it is necessary to eliminate the first asynchronous mode before the voltage and frequency of the network in the area of the electrical center drop to dangerous values. To implement this measure, the above parts of the electric power system must operate separately. The ideal point of separation is the point of the current separation before the emergency mode, therefore, in both parts of the power system, the power balance will be maintained, and the frequencies will be close to normal values. As the practice of eliminating the consequences of accidents 
in powerful power systems shows, such a separation is often unrealistic, since the asynchronous mode usually occurs not near the current separation point, but, on the contrary, near heavily loaded power lines.

\section{Conclusion}

Based on this, the division of the electric power network is carried out in places that correspond to the minimum power imbalance from among the possible. In addition, the elimination of the asynchronous mode can be carried out by resynchronizing individual power systems that have gone out of synchronism, unloading some of the generators of power plants and (or) disconnecting the load in the excess part of the power system.

Thus, taking into account all the above aspects of the management of an electric power system containing several parallel power sources, the operational dispatch personnel must ensure:

- balance of active and reactive power of the consumer and the load of power plants, taking into account external and internal flows of electricity;

- minimization of material costs for the production and transmission of electricity, provided that the necessary reliability is ensured, taking into account the operating conditions (components of the power balance, the scheme of the electrical network and the provision of power plants with energy resources);

- maintaining the required reserves of active and reactive power, taking into account the power of distributed generation sources.

\section{References}

[1] J. Hazra, A.K. Sinha, Congestion management using multiobjective particle swarm optimization, IEEE Transactions on Power Systems 22, 4, 17261734 (2007)

[2] W. Huang, et al., A review on microgrid technology containing distributed generation system [J], Power System Technology 9, 006 (2009)

[3] P. Kundur, N.J. Balu, M.G. Lauby, Power system stability and control (New York, McGraw-hill, 1994) 7

[4] A.V. Varganova, On methods of optimizing the operating modes of electric power systems and networks, Bulletin of the South Ural State University 17, 3 (2017)

[5] T.A. Filippova, A.G. Rusina, Modern concepts for optimizing the regimes of electric power systems, Materials of the All-Russian Conference Energy of Russia 21, 1-4 (2010)

[6] E.I. Gracheva, O.V. Naumov, Vliyanie rezhima raboty na veroyatnostnye kharakteristiki elektricheskikh ustroystv (Operating Mode Influence on Probability Characteristics of Electric Devices), Journal of engineering and applied sciences 11, 1, 2934-2938 (2016)
[7] E.I. Gracheva, O.V. Naumov, Estimation of Power Losses in Electric Devices of the Electrotechnical Complex, International Conference on Industrial Engineering, Applications and Manufacturing (ICIEAM), 6 (2019)

[8] D.S. Tolibjonovich, T.M. Islomovna, M.D. Saidulloevna, Modeling of starting transition processes of asynchronous motors with reduced voltage of the supply network, European Journal of Electrical Engineering 22, 1, 23-28 (2020) DOI: 10.18280/ejee. 220103

[9] M.I. Toshkhodzhaeva, Sravnitel'nyy analiz mekhanicheskikh svoystv traditsionnykh i vysokotemperaturnykh provodov vlep - $110 \mathrm{kV}$ (Comparative analysis of the mechanical properties of traditional and high-temperature vlep wires - $110 \mathrm{kV}$ ), Izvestiya Tul'skogogo sudarstvennogo universiteta, Tekhnicheskienauki 3, 169-175 (2017)

[10] M.I. Toshkhodzhaeva, A.A. Khodzhiev, Osobennosti diagnostirovaniya vlep-110 kv v usloviya khrezkokontinental'nogo klimata (Features of diagnosing high-voltage power lines of $110 \mathrm{kV}$ in a sharply continental climate), Izvestiya Tul'skogogo sudarstvennogo universiteta, Tekhnicheskienauki 2, 364-369 (2019)

[11] P.P. Barker, R.W. De Mel, Determining the impact of distributed generation on power systems, I. Radial distribution systems, Power Engineering Society Summer Meeting, IEEE 3, 1645-1656 (2000)

[12] E. Lakervi, E.J. Holmes, Electricity distribution network design, IET 21, 130-142 (1995)

[13] W. Li, et al., Reliability assessment of electric power systems using Monte Carlo methods (Springer Science \& Business Media, 2013) 540 